\title{
Effect of antioxidant and adsorbent on broiler meat production and consumer qualities
}

\author{
Irina Ktsoeva ${ }^{1, *}$, Rustam Abdulkhalikov ${ }^{2}$, Rustem Temiraev $^{1}$, and Svetlana Savkhalova ${ }^{2}$ \\ ${ }^{1}$ Gorsky State Agrarian University, 37 Kirova Str., 362040 Vladikavkaz, Russia \\ ${ }^{2}$ Kabardino-Balkarian State Agricultural University named after V. M. Kokov, Lenin Avenue, 1V, \\ 360030 Nalchik, Russia
}

\begin{abstract}
To reduce the risk of aflatoxicosis, antioxidants have proven to be effective feed additives in combination with adsorbents as excellent inhibitors of intoxication processes in the poultry body. The study purpose was to determine the effect of Tox-O adsorbent in combination with OxyNil antioxidant drug on the broiler meat production and quality and reduce the risk of aflatoxicosis. It was demonstrated that to optimize meat production in the diets of farmed poultry with a tolerant amount of $\mathrm{B}_{1}$ aflatoxin, it is necessary to introduce Oxy-Nil antioxidant in the amount of $600 \mathrm{~g} / \mathrm{t}$ and Tox-O adsorbent in the amount of $750 \mathrm{~g} / \mathrm{t}$ of feed. Due to synergistic effect of these drugs, the nutritional value of poultry meat was optimized, which was expressed in control group comparison in the enrichment of pectoral muscle samples with dry matter and protein. When feeding tested drugs in pectoral muscle samples of chickens of experimental group III, the value of meat biological usefulness was improved.
\end{abstract}

\section{Introduction}

In modern years, one of the most acute problems considered by specialists in the field of feed production is a high level of compound feed quality during storage. Moreover, these ingredients, used in poultry feed formulation, first of all, become contaminated with molds. The latter secrete extremely dangerous toxic compounds - mycotoxins. These toxins are considered to be natural "pollutants" of compound feed and poultry products used for food $[1,2,3]$.

It is also known that the main contamination sources of grain ingredients with mycotoxins during their ripening, transportation and storage of crops is the so-called "field" mold, that is, in natural conditions, these fungi are already present on the grain surface. But during long-term storage in violation of the requirements and operating mode of storage facilities, there is already a process of "secondary contamination of grain components with mycotoxins, which most often prevails over primary mold contamination in the field. First of all, it resulted in excessive contamination of poultry feed ingredients with mold poisons myctoxins. At the same time, $\mathrm{B}_{1}$ aflatoxin, a producer of Aspergillus fungi, poses a particular danger to the poultry organism and its products $[4,5,6]$.

\footnotetext{
${ }^{*}$ Corresponding author: zarina kt@mail.ru
} 
To avoid the risk of aflatoxicosis, as well as reduce the growth energy and quality characteristics of broiler meat, specialists in the field of feed production are developing methods to detoxify this mold poison. According to some researchers $[7,8,9]$, one of the most effective methods to reduce the risk of this mycotoxicosis in poultry is the intake of adsorbent drugs in the feed. There are new generation drugs that are also inhibitors for molds. Besides, to reduce the risk of aflatoxicosis, antioxidants have proven to be effective feed additives in combination with adsorbents as excellent inhibitors of intoxication processes in the poultry body. They are also involved in the elimination of mold poisons from poultry body, accompanied by the optimization of broiler meat production and quality $[10,11]$.

Considering the above, the study purpose was to determine the effect of Tox-O adsorbent in combination with Oxy-Nil antioxidant drug on the broiler meat production and quality and reduce the risk of aflatoxicosis.

\section{Materials and methods}

To solve this problem in the steppe zone of the Republic of North Ossetia - Alania on four groups of meat chickens of the Ross-308 cross, 100 chickens in each, an experiment was performed according to the scheme shown in Table 1.

Table 1. Substantiation of the research concept.

\begin{tabular}{|c|c|}
\hline $\begin{array}{c}\text { Group of } \\
\text { broilers }\end{array}$ & Compound feeds and doses of drug additives \\
\hline Control & Formulation of standard compound feed with a tolerant dose of $\mathrm{B}_{1}$ \\
aflatoxin (SCF)
\end{tabular}

The duration of broilers farming for meat during this experiment was six weeks.

The standard complete poultry feed was based on cereal (barley and wheat) and protein (sunflower meal) components, infected with Aspergillus fungi. To comply with the tolerant dosage of $B_{1}$ aflatoxin - $0.25 \mathrm{mg} / \mathrm{kg}$ [12], these ingredients, contaminated with the Aspergillus fungus were mixed with other safe (for this mycotoxin) components of poultry compound feeds using standard dispensers.

The economically useful features of the experimental meat chickens were determined using generally accepted approaches.

Control slaughter after the experiment for broilers of compared groups was performed according to the standard method [13].

The obtained digital experimental material after the study was processed by the statistical method with the Student's test of validity.

\section{Results and Discussion}

The detoxification efficiency of mold toxins by introducing adsorbents, as well as biologically active compounds into the diet, is often accompanied by an increase in the viability of young poultry, that is why we present livability indicators of meat poultry in compared groups in Figure 1. 


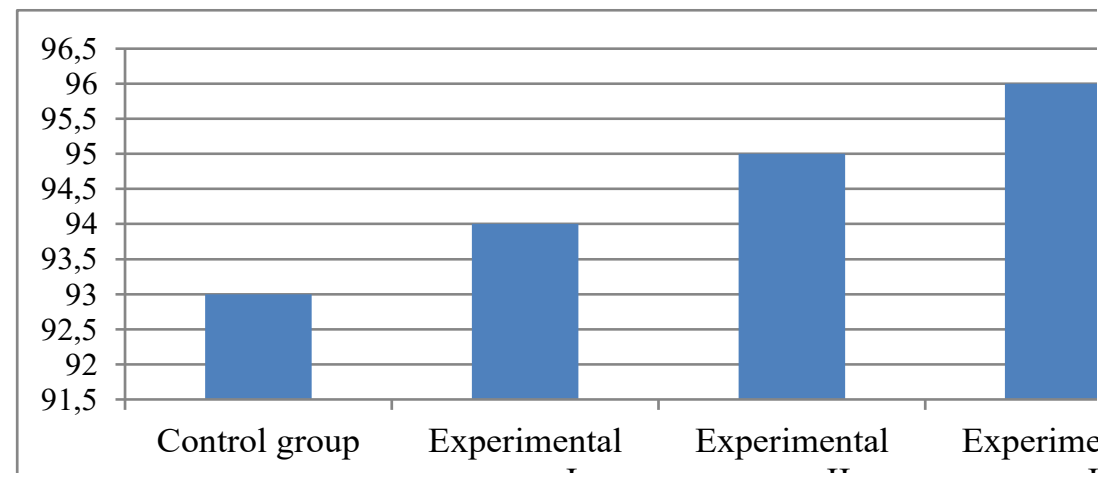

Fig. 1 - Poultry livability in compared groups, \%.

It was determined that due to the better mycotoxin elimination when feeding in the composition of compound feed instead of an adsorbent and an antioxidant, broilers of experimental group III surpassed their alternatives in the control group by $3.0 \%$ in terms of livability.

The influence level on the growth rate of broilers, fed with the drug, special attention should be paid to changes in their average daily gains (Fig. 2).

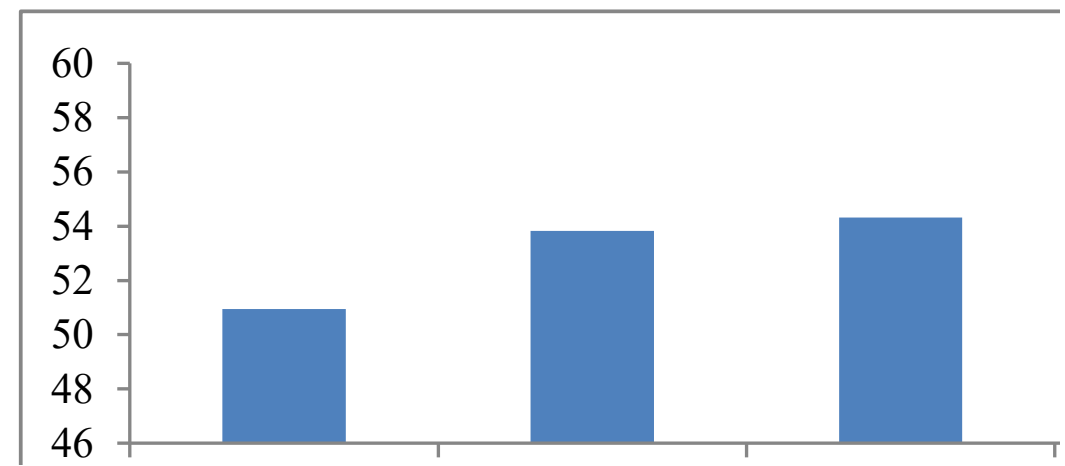

Fig. 2. Average daily poultry gains in compared groups, g.

During the experiment, with the joint introduction of these feed additives into the rations, meat chickens of experimental group III were distinguished by the highest level of growth energy, which outstripped the bird of the control group in terms of the average daily body mass gain by $12.63 \%(\mathrm{P}>0.95)$.

At the same time, it was important to evaluate the efficiency of Tox-O adsorbent effect in combination with Oxy-Nil antioxidant drug on feed conversion, studied by calculating the cost of compound feed per unit of absolute gain in poultry of compared groups (Fig. 3). 


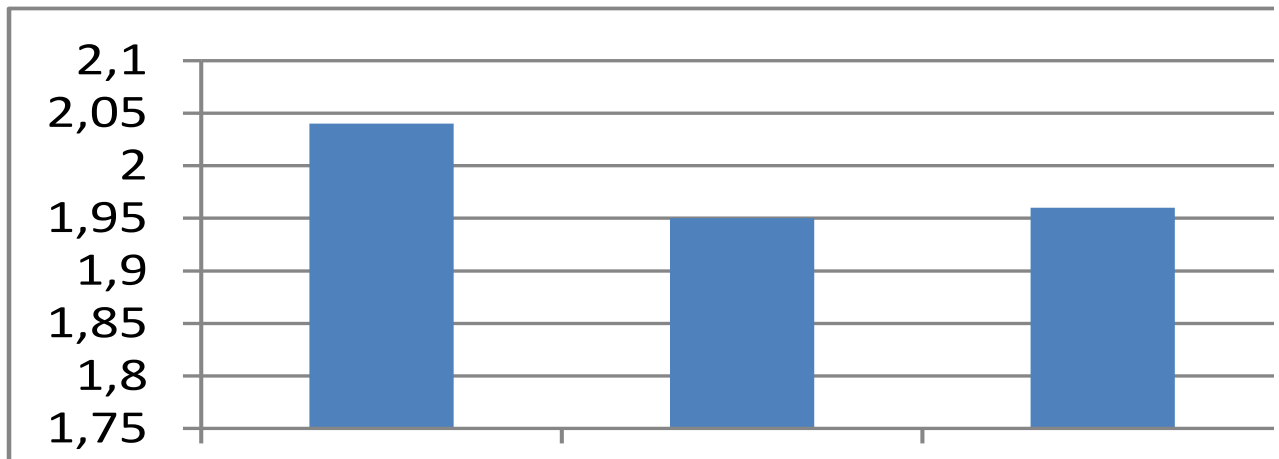

Fig. 3 - Cost of compound feed per unit of gain in broilers, kg.

Based on meat poultry production data, more efficient use of compound feed during these experiments was observed in poultry broilers of experimental group III, in comparison with control equivalents, consumed $8.82 \%$ less compound feed per kilogram of body mass gain.

The effect of feed drugs on poultry meat products depends on its slaughter indicators, estimated by the mass yield of half-dresses and dressed poultry (Fig. 4) and the slaughter yield indicator in broilers of compared groups (Fig. 5).

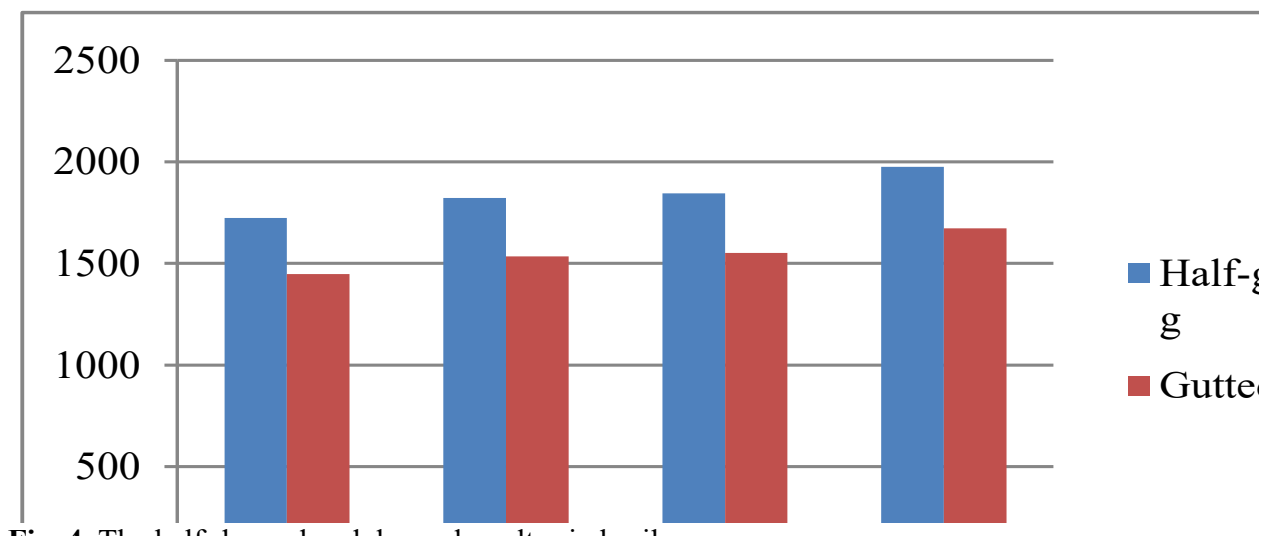

Fig. 4. The half-dressed and dressed poultry in broilers, g.

In the present experiment, due to synergistic effect between tested feed drugs, it was possible to achieve an increase in detoxification capabilities in the poultry body while reducing the risk of aflatoxicosis. Considering above mentioned, there was an improvement in the slaughter parameters in meat chickens of experimental group III, as evidenced by their statistically significant $(\mathrm{P}>0.95)$ superiority in terms of the half-dressed poultry mass by $14.62 \%$, dressed - by $15.45 \%$, as well as slaughter yield - by $0.69 \%$. 


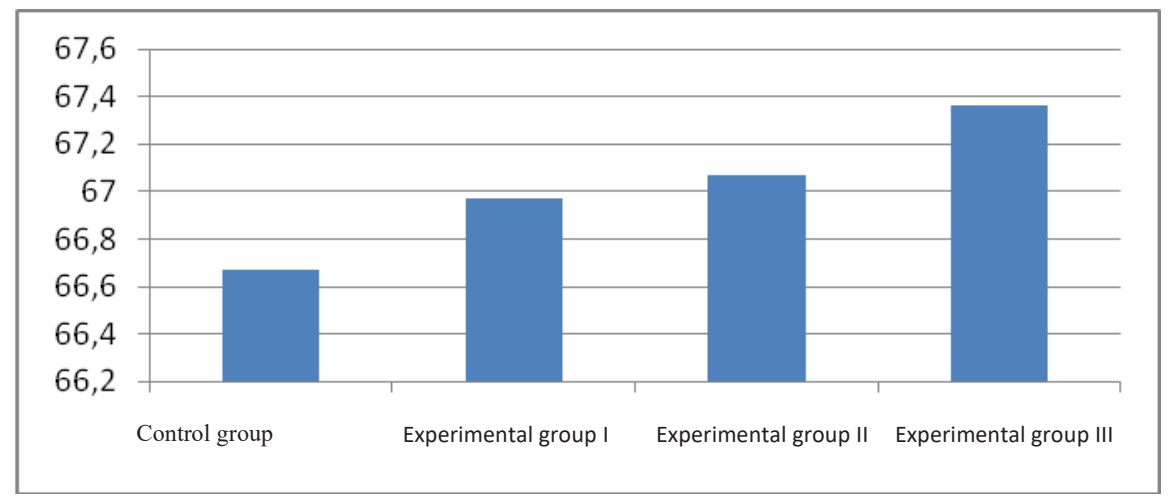

Fig. 5. Slaughter yield in experimental broilers, $\%$.

The consumer qualities of poultry meat are primarily determined by its chemical composition parameters. These indicators are greatly affected by ecological characteristics of consumed feed, as well as efficient elimination of various toxins from the body of fattened broilers, including mold.

Considering the above, in the presence of a tolerant amount of $\mathrm{B}_{1}$ aflatoxin in the consumed mixed feed, the effect of Tox-O adsorbent in combination with Oxy-Nil antioxidant drug on the main parameters of the chemical composition of pectoral muscle samples of broilers from compared groups was studied. The data is shown in Figure 6.

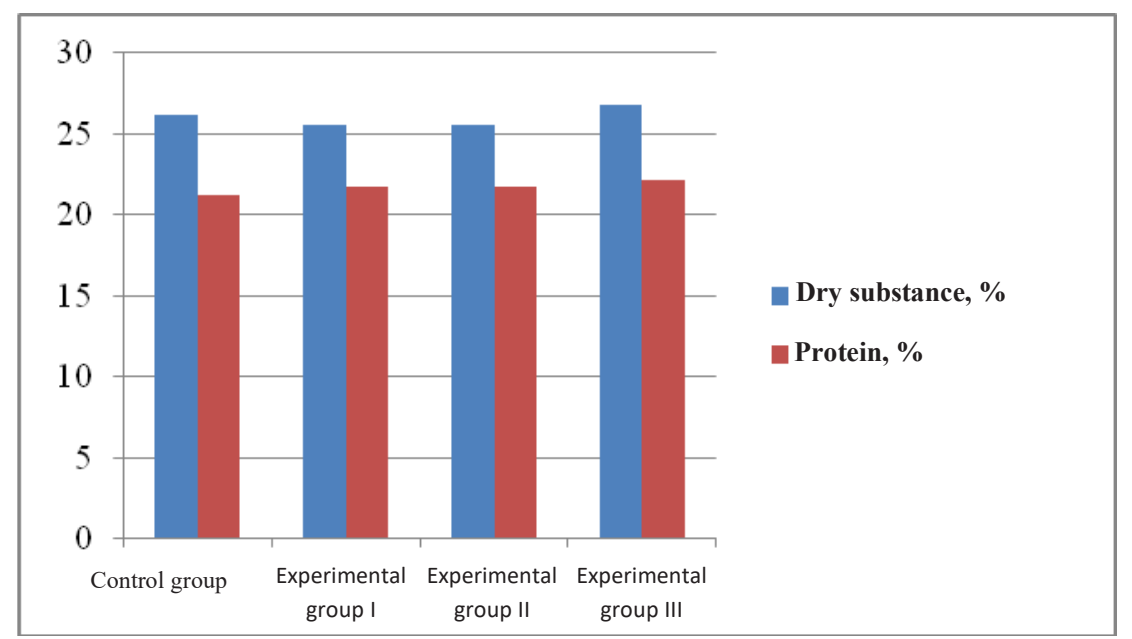

Fig. 6 - Chemical composition of poultry meat samples of compared groups, $\%$.

As shown by study results, in the course of this experiment, with combined additions of these drugs to the compound feed, a positive effect on the chemical composition of broiler meat samples from experimental group III was established. It was demonstrated in comparison with control group equivalents in a statistically significant $(\mathrm{P}>0.95)$ enrichment of the pectoral muscle samples with the presence of a dry matter mass fraction by 0.61 and protein - by $0.95 \%$ with a parallel lipid reduction - by $0.38 \%(\mathrm{P}>0.95)$, respectively.

At the same time, the nutritional value of poultry meat is largely due to its biological usefulness, studied by protein-quality indicator (PCI) in pectoral muscle sample, the ratio between the mass fraction of the amino acids tryptophan and hydroxyproline. The proteinquality indicator value of poultry meat in compared groups is shown in Figure 7. 


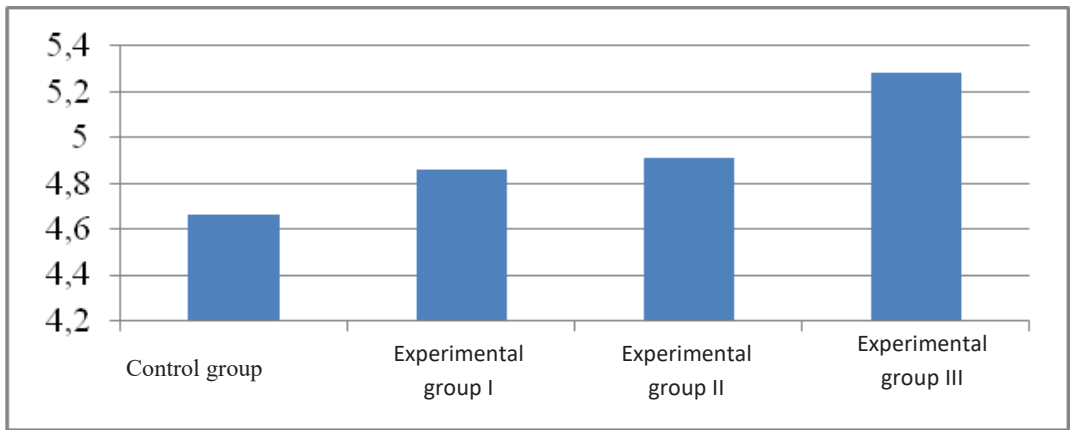

Fig. 7. The protein-quality indicator of poultry meat of the compared groups, units

According to study results, it was found that when feeding in the poultry feed composition with a tolerant amount of mold poison $\mathrm{B}_{1}$ aflatoxin in these pectoral muscle samples of chickens of experimental group III, in comparison with their control equivalents, there was a significant $(\mathrm{P}>0.95)$ increase in the protein-quality indicator value of poultry meat by $12.54 \%$.

\section{Conclusions}

1. To optimize the productivity and nutritional value of poultry meat, it is necessary to introduce Oxy-Nil antioxidant in the amount of $600 \mathrm{~g} / \mathrm{t}$ and Tox-O adsorbent in the amount of $750 \mathrm{~g} / \mathrm{t}$ of feed into diets containing a tolerant amount of $\mathrm{B}_{1}$ aflatoxin.

2. Due to the more effective detoxification of the specified mold poison due to synergistic effect of these feed drugs, the nutritional value of poultry meat was optimized, expressed in comparison with control group equivalents in a reliable $(\mathrm{P}>0.95)$ enrichment of pectoral muscle samples with dry matter by 0.61 and protein - by $0.95 \%$ with a parallel reduction in lipids - by $0.38 \%(\mathrm{P}>0.95)$.

3. When feeding the tested drugs in the composition of compound feeds at a tolerant level of mycotoxin in the pectoral muscle samples of meat chickens of experimental group III in comparison with their control equivalents, an increase in the value of the proteinquality indicator of poultry meat by $12.54 \%$ was observed.

\section{References}

1. R. Kh. Gadzaonov, A. A. Stolbovskaya, A. A. Baeva, G. K. Kibizov, Poultry Breeding, 4, 23-24 (2009)

2. R. B. Temiraev, Z. T. Baeva, N. G. Ter-Teryan, A. A. Gazdarov, L. R. Tebloeva, (Cheese and Butter Making, 5, 56 (2009)

3. F. F. Kokaeva, R. B. Temiraev, A. A. Stolbovskaya, O. Yu. Leontyeva, Meat Industry, 2, 59-61 (2012)

4. R. B. Temiraev, Z. R. Ibragimova, L. H. Albegova, M. Sh. Gadieva, A. T. Bagaeva, S.K. Abaeva, Storage and Processing of Agricultural Raw Materials, 11, 74-76 (2007)

5. V. K Temiraev, V. R. Kairov, R. B. Temiraev, Z. A. Kubatieva, V. M. Gukezhev, Ecology, Environment and Conservation, 23(1), 554-561 (2017)

6. S. Kononenko, R. Temiraev, Z. Baeva, A. Gazdarov, Compound Feed, 6, 104-105 (2011) 
7. A. A. Baeva, A. A. Stolbovskaya, F. F. Kokaeva, Z. G. Dzidzoeva, Yu. S. Tseboeva (Yu.S. Gusova), O. Yu. Leontyeva, G. K. Kibizov, Proceedings of the Kuban State Agrarian University, 4(13), 179-182 (2008)

8. R. Temiraev, S. Lokhova, I. Kokoeva, D. Tsarukaeva, Poultry Breeding, 10, 35 (2006)

9. R. B. Temiraev, M. K Kozhokov, S. K Cherchesova, F. F. Kokaeva, I. R. Tletseruk, Journal of Environmental Management and Tourism, 8, 3(19), 567-573, (2017)

10. L.V. Tsalieva, R. B. Temiraev, S. I. Kononenko, B. A. Dzagurov, M. S. Gazzaeva and S. A. Grevtsova, Journal of Pharmaceutical Sciences and Research, 9(12), 2397-2400 (2017)

11. R. B. Temiraev, S. G. Kozyrev, S. I. Kononenko, A. A. Baeva, L. A. Bobyleva, A. L. Kalabekov, Journal of Pharmaceutical Sciences and Research, 9(6), 780-784 (2017)

12. Y. A. Yuldashbaev, R. B. Temiraev, V. V. Tedtova, K. B. Temiraev, R. V. Osikina, M. S. Gazzaeva, L. H. Shugusheva, I. K Sattsaeva, M. M. Udychak, Journal of Livestock Science, 11, 8-13 (2020)

13. L. A. Vityuk, A. A. Baeva, I. V. Kochieva, A. A. Stolbovskaya, S. I. Kononenko, A. V. Yarmoc, I. R. Tletseruk, L. A. Bobyleva, B. G. Tsugkiev, I. K Sattsaeva, Pollution Research, 36(4), 748-754 (2017) 